\title{
Effects of Grandchildren's Love Language Program on Depression among Thai Older Adults
}

\section{Saifon AEKWARANGKOON* and Naiyana NOONIL}

School of Nursing, Walailak University, Nakhon Si Thammarat 80161, Thailand

('Corresponding author's email: asaifon@wu.ac.th)

Received: 24 January 2018, Revised: 12 November 2018, Accepted: 16 January 2019

\begin{abstract}
Depression in older adults has remained 1 of the major detrimental public health problems both worldwide and in Thailand. Among the myriad healing approaches, mental attachment on the basis of grandchildren's love language is favorably perceived by Thai older adults with depression. The purpose of this quasi-experimental study was to evaluate the effects of grandchildren's love language program on reducing depression among Thai older adults. Eighty Thai older adults with mild to moderate depression levels received the so-called "Love Language of Grandchildren Program" $(n=40)$ and usual care $(n=40)$. The Nine-Question Scale (9Q) and Hamilton Rating Scale for Depression (HRSD) were distributed at the pre- and post-treatment and at the 12 and 24-week of the follow-ups. The treatment effectiveness was evaluated by using Multivariate Analysis of Covariance (MANCOVA). The 9Q and HRSD scores revealed a significantly neutralized depression for those in love language of grandchildren program and, on the other hand, no decline was observed in the usual care's participants. Love language of grandchildren program effectively reduced 9Q and HRSD symptoms of emotional, cognitive, behavioral, and physical conditions respectively. It was also more effective than the usual care in reducing mild to moderate symptoms of depression $(p<0.05)$. The findings provide better understanding on how grandchildren approach to prevent depression for Thai older adults in a family and community, and can be used to guide further capacity development for grandchildren who provide helping to this group.
\end{abstract}

Keywords: Grandchildren's Love Language, Depression, Older adults

\section{Introduction}

Depression is a major public health problem worldwide [1]. A number of new cases of depression and depression-related suicides have been continually stacking up annually around the world including in Thailand $[1,2]$. Thai older adults have been identified as the population group with the high probability risk for depression [2-4]. The prevalence of depression among Thai older adults was 36.9 percent and more specifically, one third of the elderly patients suffering from chronic diseases had depression [3].

Depression is considered as one of the leading causes of illness, disability, and mortality [1,2], casting adverse impacts on people's abilities to carry out even the simplest everyday tasks, relationships with family, friends, and also the ability to earn a living [4-6] and, at worst, escalating to suicide [1,2]. In Thailand, depression is a common problem experienced by Thai older adults, potentially developing into attempted-and-completed suicide [1,2,5]. The Thai government has spent high costs trying to solve these problems $[2,6]$.

Increased risk of depression in Thai older adults is highly associated with a negative relationship with significant persons [7,8]. In other words, they are more likely to be depressed upon losing attachment, love, connection, and caring [7]. As a result, this perception serves as a breeding ground for the feeling of guilt, low self-esteem, helplessness, powerlessness, depression, and eventually suicide $[3,7,9]$. The negative relationship can precede the onset of depression, occur as a symptom of depression, 
or develop as a learned coping response to other symptoms of depression [3,5]. Early depression treatment by means of enhancing positive relationship among older adults in a family and community is strongly recommended $[2,6,9]$.

In an attempt to counteract depression among Thai older adults, a variety of effective treatments or programs utilizing positive interpersonal relationships have been devised such as CBT with supportive, brief treatment with supportive, interpersonal therapy, etc., (3-4,6-7). Likewise, health care personnel, health volunteers or caregivers are engaged in intensive trainings orienting them towards specific treatments, most of which operate in compliance with fixed patterns intended for fast-track effects $(4,6)$. However, little research into this area has addressed this issue, especially with the focus on weaving positive interpersonal relationships with significant persons, such as family members, although, in fact, this is not only the simplest, but also the easiest treatment in a daily life's context, providing effective long-term counteraction against the depressive symptoms (7-10). Meanwhile, love language consistently provided by significant persons has been identified as one of the most profound approaches to help ease depressive symptoms in older adults $(7-8,10)$.

Mental attachment using the love language from grandchildren can translate into a powerful cure for Thai older adults with depression $[3,4,7]$. Previous studies profoundly revealed the use of love language in a family being reported as an effective depression treatment and prevention for those predisposed to the symptom onset $[7,8,10,11]$. In a traditional Thai rural community context, mostly extended-family households, older adults reside together with their grandchildren. However, no tangible measures have come at play to test the effectiveness of the love language between grandparent and grandchildren. Conceptually, love language is defined by five ways in which people speak and comprehend emotional love, involving 1) consistently using words of affirmation to express love emotionally, such as verbal compliments or appreciation; this functions as powerful communicators of love, constructing and reinforcing the tremendous power of love through verbally affirming each other, 2) spending quality time to give each other individual and undivided attention, 3) receiving and offering gifts carrying sentimental values for each other, 4) performing acts of service in the interest of others by cooking, setting a table, massaging with a positive spirit, and 5) communicating emotional love through physical contacts. It has been proved that being held, stroked, and kissed constitute healthier emotional life [12-14]. With its simplicity, grandchildren specifically trained in the program personnel can put the concept into practice in a long run period to improve the older adults' psychological well-being.

In this study, the love language of grandchildren program is of special interest for helping individuals to be loved, cared, and replace negative relationship associated with symptoms of depression in older adults. It is a feasible method assimilating well with the Thai community context. The program itself also conceptually focuses on eliminating any inappropriate or negative relationships, whereas the program provides the step-by-step approach to achieve the interpersonal relationship-building goals [10,12-14]. Substantial literature from the last half-century has elaborated on the importance of early help provision to prevent and treat mental health problems, among others being depression among older adults in family and community $[2,4,6,7]$.

Early depression counteractions in older adults are inadequately provided in many parts of Thailand [2]. Further research is needed to provide stakeholders better comprehension of what older adults need and how to connect with them the best in order to encourage responsible mental health and also to help them prevent and promote their mental health. Earlier studies emphasized specific effective treatments that must be administered by well-trained health care personnel, so due to the shortage of heath care manpower in Thailand, it may take massive effort for such treatments to measure up to its fullest capacity (3,6-7). In addition, the effects of personnel-supervised care wear off after a short period of time, unlike consistent inclusion of natural booster on a daily basis through the simple but profound love language treatment by family members $(3,7,10)$. The purpose of this study was to evaluate the effectiveness of the love language of grandchildren program compared to a usual care session. The research hypothesized that the love language program of grandchildren would be more effective than the usual care in reducing mild to moderate symptoms of depression among Thai older adults. 


\section{Materials and methods}

Study design

A quasi-experimental, pretest-posttest control group design with 2 follow-up times was conducted from December 2015 to April 2016 to test the effectiveness of the grandchildren's love language program to reduce depression among Thai older adults with mild to moderate depression levels.

Population and Samples: Older adults with mild to moderate depression screened by the NineQuestion Scale (9Q scores of 7 to 18) [15], and Hamilton Rating Scale for Depression (HRSD scores of 8 - 17) [16], living in 4 villages of Thasala District, Nakhon Si Thammarat Province, Southern Thailand. Of all 15 villages, 4 was selected using purposive sampling recruiting participants being aware of this mental issue in older adults and volunteering to participate in the study. Sample size of 28 was calculated based on a statistical power of 0.80 at a 0.05 significance level to detect an effect size of 0.77 [17]. The decision to over-sample by at least 35 percent was made in order to reduce the design threat of sample attrition. The total study sample was 80 older adults with 40 older adults in each group.

Random selection methods were used to assign each 2 villages to either treatment or control groups. Subjects in the treatment group $(n=40)$ received the love language of grandchildren program, whereas subjects in the control group $(n=40)$ received the usual care. To prevent design contamination or diffusion of treatment between these 2 groups, the control group did not know about the treatment group as a result of separate settings. Additionally, the researchers interviewed the subjects in search of any design contamination. Eligible subjects were older adults, ranging from 60 -year old and over, with no diagnostic or treatment history of depression and substance abuse. They would be excluded if they reported a history of attempted suicide or self-injury or were currently abusing alcohol or drugs, receiving treatment for a mood disorder, receiving cognitive treatment for any condition, or being enrolled in a behavior modification program. The number of depressed older adults in 4 villages is $89,92,80$ and 87 respectively. After being clearly informed of the study detail, 15 qualified older adults dropped out, 5 of whom is actively undergoing substance abuse and 10 of whom simply refused to join the program, all the rest who are willing to participate in the study were divided by simple random sampling into groups until the required number is reached.

\section{Outcome measures}

9Q and HRSD scores were used to measure the treatment's effectiveness within and between groups across 4 time points at pre-and post-treatment and at the $12^{\text {th }}$ and $24^{\text {th }}$ - week follow-up. The body of the literature suggested using 9Q and HRSD, a self-report and a professional report respectively, because both of them qualify for evaluating depression.

The Nine-Question Scale (9Q) is a 9-item self-rated depression assessment. 9Q is brief, and was developed to correspond to the Diagnostic and Statistical Manual of Mental Disorders, criteria for major depression. Respondents rate their symptoms for the previous 2-weeks as none of the time (0), rarely for 1 - 7 day (1), often for $>7$ day (2), to most or all of the time (3). Acceptable evidence of internal consistency in psychiatric and non-psychiatric populations has been reported. The $9 \mathrm{Q}$ defines scores of 0 - 6 as no depression, $7-12$ as mild depression, $13-18$ as moderate depression, and $\geq 19$ as severe depression. The scores have proved to be effective at distinguishing between depressed and nondepressed Thai older adults [15]. This instrument had been trialed by 30 older adults in the other village bearing strong resemblance to the research subjects. The alpha coefficient for this study was 0.85 .

Hamilton Rating Scale for Depression (HRSD) is a 17-item clinician-rated assessment of depression $[16,18]$. The first author performed all HRSD ratings in the study. Respondents rate their symptoms for the previous 2 -weeks from symptom absent to symptom present $(0-2,0-4)$. The higher value indicated the more severe of the symptom rating. HRSD was back-translated in Thai version. The Lotrakul, Sukanich, \& Sukying's Thai translation of the HRSD was used in this study which defines scores of $8-12$ as mild depression, scores of 13 - 17 as less than major depression, scores of 18 - 29 as major depression, and scores of 30 and higher as an indication of distress possibly due to more than just major depression or psychotic depression. The Thai translated HRSD has proved to be a reliable and valid measure [16]. This instrument 
was trialed by 30 older adults in the other village bearing strong resemblance to the subjects. The alpha coefficient for this study was 0.89 .

\section{Love language of Grandchildren program}

Love language of grandchildren program is grounded on the 5 love language concepts [14] consisting of 7 steps and the process was developed as interpersonal relationship. In 6 individual sessions provided over the course of 6 weeks, the treatment delivered a structured interpersonal bonding with love language treatment being combined with a series of individual treatments. The treatments were designed to construct positive interpersonal interactions with grandchildren for the purpose of promoting positive coping responses, addressing depression-related personal and social problems, and promoting the treatment gains achieved by Love Language of Grandchildren program.

The love language of grandchildren program followed 7 steps. These include making a small talk, assessing sadness, obtaining feedback information to reduce stigma, encouraging expression of feeling, encouraging expression of perception, encouraging expression of expectations, and putting 5 love language concepts into practice with older adults. The small talk induces positive relationship between older adults and grandchildren through general questions easy to answer. Feedback was accurate symptom information based on the older adult's 9Q and HRSD scores, the rate of older adult depression in the same province, general etiology information, and information about common responses to symptoms of depression. Feedback was intended to increase symptom awareness and decrease the social stigma of depression. Encouraging expression of feeling addressed the impact of depression on the older adult's life, the need to learn to release suffering feeling. Encouraging expression of perception was intended to identify negative feelings. Encouraging expression of expectations was intended to increase awareness of self-management as an effective means of achieving desired changes. Putting 5 love language concepts into practice with the older adults by the grandchildren was intended to connect positive energy for themselves and others. Both steps were intended to encourage and promote positive connection for one's self and others.

Six-weeks of weekly positive interpersonal interactions with grandchildren and older adults were growth in the process of love language program. The first session was for the older adult and the grandchildren to establish the treatment relationship, practice each step, and assign self-management homework. Then, 2nd to 5th sessions were used to guide the older adult's self-evaluation of the selfmanagement homework completed since the prior session, and based on this evaluation, practice new alternative methods of meeting personal needs and then assign new self-management homework. Lastly, the final 6th session was used to review and reevaluate proficiency of each step by practicing the entire process with the grandchildren and terminating the treatment relationship.

\section{Treatment providers}

Thirty grandchildren are volunteers from 2 villages in Thasala District who provide love language treatment to the older adults with mild to moderate depression. The criteria to select grandchildren include an age range between 9 - 20 years, living with or near depressed older adults, and being willing to participate in this study. Each volunteer would work with 2 to 3 depressed older adults in their family and nearby homes. Hence, as a prerequisite, they were required to complete a 4 day workshop in love language treatment and, with no exception, need to be trained and pass the test prior to the start of the program and, more importantly, to ensure that all the trained grandchildren measure up to the same standard or ability, their knowledge, attitude and skills were thoroughly assessed through role plays, discussions, and skills in each step. No pass status was granted unless they met the same criteria and received pass scores for using treatment. The trainer was the first author. Grandchildren may refer severely depressed older adults to the registered nurse employed at community hospitals. Health volunteers at the control villages provided usual care with no additional training. In the control group, grandchildren consistently provided natural relationship boosters common in daily life such as talking to older adults about daily activities. 


\section{Ethical issues}

This research is a part of the research entitled "Development Youth Volunteer for Caring Older People with Depression in the Community". Before collecting the data, an ethical agreement had been granted in 2016 from the Committee on Human Rights Related to Research Involving Human Subjects, Walailak University, Thailand (Protocol Number 16/077). The ethical issues were concerned with both depressed older adults and grandchildren who participated in this study. The ethical issues during this study process were involved with the subjects' independence, intimacy, and anonymity. The subjects were informed of both objectives and detail of the study underlining clarification of potential risks and benefits of the study. The participants were made aware that they have a right to choose whether to participate in the program and can withdraw from the program anytime. The subjects in the control group would receive the treatment once the treatment had been found effective. Informed consent was retrieved from the subjects who agreed to be involved in the study. In the grandchildren group, their parents or guardian who agreed had also been informed of an ethical issue and sign informed consent prior to their children's participation in the study.

\section{Data analysis}

Descriptive statistics, frequencies, percentages, means, and standard deviations were computed to summarize the data. Differences between the treatment and control groups were evaluated using independent t-tests for the 9Q and HRSD scores and Chi square for the characteristics between 2 groups. Treatment effectiveness was evaluated with separate repeated measures multivariate analysis of covariance (MANCOVA) of the 9Q and HRSD scores. Testing of assumption of MANCOVA such as normality, independence of observations and homogeneity of variances were met before further interpretation of the results.

\section{Results}

Thirty grandchildren participants aged between 9 and 19-year old $(M=14.54, S D=2.78)$. The majority was female (66.67\%), while the rest was male $(33.33 \%)$. All the participants were Muslims, studying in elementary school (46.67\%) and secondary school (53.33\%); they lived with parents and extended family $(93.33 \%)$ and lived with only grandparent $(6.67 \%)$; the types of family's occupation were general employment $(80.00 \%)$ and trade $(20 \%)$; their family incomes ranged from 6,000 to 15,000 Bahts $(M=10,505, S D=1,076)$; perceived family's relationship is good $(90.00 \%)$, and problematic $(10.00 \%)$.

In the depressed older adults participant group, comparisons between treatment and control groups (Table 1) revealed no significant differences in association with age, gender, religion, marital status, educational level, health status, number of grandchildren, number of family members, relationship with family, family occupation, and perceived adequacy of family income (all $p$ 's $>0.05$ ). Since the 2 groups differed in terms of perceived adequacy of person income only, this variable was treated as a covariate in subsequent between-group comparisons. 
Table 1 Demographic characteristics of the treatment and control groups.

\begin{tabular}{|c|c|c|c|c|}
\hline Variables & $\begin{array}{c}\text { Total } \\
(N=\mathbf{8 0})\end{array}$ & $\begin{array}{c}\text { Numbers (\%) } \\
\text { Treatment Group } \\
(n=40)\end{array}$ & $\begin{array}{c}\text { Numbers (\%) } \\
\text { Control Group } \\
(n=40)\end{array}$ & $p$ \\
\hline \multicolumn{5}{|l|}{ Age $(M=68.87, S D=5.45)$} \\
\hline $60-70$ & $39(48.75)$ & $20(50.00)$ & $19(47.50)$ & 0.78 \\
\hline $71-80$ & $28(35.00)$ & $13(32.50)$ & $15(37.50)$ & \\
\hline$>80$ & $13(16.25)$ & $7(17.50)$ & $6(15.00)$ & \\
\hline \multicolumn{5}{|l|}{ Gender } \\
\hline Female & $51(63.75)$ & $25(62.50)$ & $26(65.00)$ & 0.75 \\
\hline Male & $29(36.25)$ & $15(37.50)$ & $14(35.00)$ & \\
\hline \multicolumn{5}{|l|}{ Religion } \\
\hline Muslim & $80(100.00)$ & $40(100.00)$ & $40(100.00)$ & 1.00 \\
\hline \multicolumn{5}{|l|}{ Marital status } \\
\hline Married & $35(43.75)$ & $18(45.00)$ & $17(42.50)$ & 0.62 \\
\hline Widowed & $45(56.25)$ & $22(55.00)$ & $23(57.50)$ & \\
\hline \multicolumn{5}{|l|}{ Educational level } \\
\hline Primary school & $41(51.25)$ & $21(52.50)$ & $20(50.00)$ & 0.84 \\
\hline Did not study & $39(48.75)$ & $19(47.50)$ & $20(50.00)$ & \\
\hline \multicolumn{5}{|l|}{ Health status } \\
\hline Live with chronic illness & $80(100)$ & $40(100)$ & $40(100)$ & 1.00 \\
\hline \multicolumn{5}{|l|}{ Numbers of grandchildren } \\
\hline $1-5$ & $62(77.50)$ & $32(80.00)$ & $30(75.00)$ & 0.68 \\
\hline $6-12$ & $18(22.50)$ & $8(20.00)$ & $10(25.00)$ & \\
\hline \multicolumn{5}{|l|}{ Number of family members } \\
\hline $1-5$ persons & $28(35.00)$ & $13(32.50)$ & $15(37.50)$ & 0.64 \\
\hline$>5$ persons & $52(65.00)$ & $27(67.50)$ & $25(62.50)$ & \\
\hline \multicolumn{5}{|l|}{ Relationship with family } \\
\hline Good & $52(65.00)$ & $25(62.50)$ & $27(67.50)$ & 0.72 \\
\hline Conflict & $28(35.00)$ & $15(37.50)$ & $13(32.50)$ & \\
\hline \multicolumn{5}{|l|}{ Family occupation } \\
\hline General employment & $54(67.50)$ & $26(65.00)$ & $28(70.00)$ & 0.67 \\
\hline Trade & $26(32.50)$ & $14(35.00)$ & $12(30.00)$ & \\
\hline \multicolumn{5}{|c|}{ Perceived adequacy of family's income } \\
\hline Enough & $46(57.50)$ & $24(60.00)$ & $22(55.00)$ & 0.62 \\
\hline Not enough & $34(42.50)$ & $16(40.00)$ & $18(45.00)$ & \\
\hline \multicolumn{5}{|c|}{ Perceived adequacy of person's income } \\
\hline Enough & $42(52.50)$ & $30(75.00)$ & $12(30.00)$ & 0.001 \\
\hline Not enough & $38(47.50)$ & $10(25.00)$ & $28(70.00)$ & \\
\hline
\end{tabular}

\section{Depression scores}

As can be observed in Table 2, the result revealed a significant decline of 9Q and HRSD scores after grandchildren's love language program but no decline was observed for the usual care. Furthermore, grandchildren's love language treatment effectively reduced 9Q and HRSD symptoms of emotional, cognition, behavioral, and physical conditions respectively. Accordingly, Love Language of grandchildren program was more effective than the usual care in reducing mild to moderate symptoms of depression. 
Love Language of Grandchildren on Depression of Thai Older Adults Saifon AEKWARANGKOON and Naiyana NOONIL

http://wjst.wu.ac.th

Table 2 Summary of repeated measures multivariate analysis of covariance (MANCOVA) and 1-way ANCOVA results $(\mathrm{N}=80)$.

\begin{tabular}{|c|c|c|c|c|c|c|c|c|c|c|c|}
\hline \multirow[b]{2}{*}{ Variable } & \multicolumn{8}{|c|}{ Time } & \multicolumn{3}{|c|}{ ANCOVA $F$ tests } \\
\hline & \multicolumn{2}{|c|}{$\begin{array}{l}\text { Pre-treatment } \\
\text { Mean (SD) }\end{array}$} & \multicolumn{2}{|c|}{$\begin{array}{l}\text { Post-treatment } \\
\text { Mean (SD) }\end{array}$} & \multicolumn{2}{|c|}{$\begin{array}{c}12 \text { weeks post- } \\
\text { treatment } \\
\text { Mean (SD) }\end{array}$} & \multicolumn{2}{|c|}{$\begin{array}{c}24 \text { weeks post- } \\
\text { treatment } \\
\text { Mean (SD) }\end{array}$} & $\begin{array}{l}\text { Group } \\
\text { Main } \\
\text { effect }\end{array}$ & $\begin{array}{l}\text { Time } \\
\text { Main } \\
\text { effect }\end{array}$ & Interaction \\
\hline \multicolumn{12}{|l|}{ Depression } \\
\hline $9 \mathrm{Q}$ & $14.48(2.67)$ & $14.37(2.54)$ & $5.21(1.63)$ & $14.87(2.54)$ & $4.45(1.67)$ & $15.58(2.35)$ & $4.12(1.25)$ & $16.78(2.68)$ & 259.98 & 16.98 & 85.49 \\
\hline
\end{tabular}

\section{Discussion}

Love Language of Grandchildren program was significantly more effective than usual care in reducing mild to moderate depression in Thai older adults. The treatment reduced 9Q and HRSD, self- and professional-rated symptoms of depression. The study findings also showed that a 6-session dose of grandchildren's love language program delivered at home produced a significant reduction in symptoms of depression that continued for 24-week.

The effectiveness of the grandchildren's love language program can be explained by the interpersonal theory that depression can be improved by a positive relationship that influences emotion, feeling, cognition, and behaviors [7,14]. Love language of grandchildren program helps the depressed older adults by encouraging positive perception and thinking and also changing their inappropriate relationships into appropriate ones [7,10-12]. Positive relationship as an environment support for depressed older adults has a positive influence on their psychological well-being, both as a direct health promoting agent and as a buffer against the negative effects of stress and depression $[7,9,19]$.

There may be interesting conjectures as to why this treatment seemed not only to work, but also to be successful over a posttest and at 12- and 24- weeks' period of time. The researcher speculates that the model of grandchildren's love language program for depression may have positive results for, at least, 3 reasons.

First, in accordance with the structured nature of the grandchildren's love language program, depressed older adults received feedback in the form of accurate information regarding his/her depression using his/her 9Q and HRSD scores compared to the incidence rates for older adults depression recorded in the same country and worldwide. Based on this activity, depressed older adults are not only aware of their depressive symptom levels but also rid of stigma from this step because they were concerned that depressive symptoms can happen to everyone as an universal psychological symptom problem $[4,9,14]$. These results are in harmony with the previous study stating that reducing stigmatization is helpful for reducing depression or psychological problems $(2,4-5)$. They also responded well in the responsibility for making changes to their emotions, thoughts, behaviors, and physicals that induce to the problems in the responsibility step [5,9]. This step consistently pointed out that people are most likely to take action when they perceive that they personally have chosen to do so.

These processes successfully reached the positive interpersonal relationship treatment goals in terms of identifying and challenging distortions in thinking patterns that contain a bleak view of oneself, one's activities, and the future $[8,19]$. The grandchildren and depressed older adults collaborating on sorting out what way the older adults tended to connect with themselves and others identified more realistic ways to connection and substituted appropriate way of connections for the previous depressive cognitive set $[5,9]$. When depressed people learned to identify distorted relationship with themselves and others and to replace them with more realistic ones, depression could be reduced $[9,19]$.

Secondly, the treatment was successful in reducing depressive symptoms which is presumably attributed to the characteristic of the love language program activities. Older adults were assisted in promoting the thorough understanding of depression and developing good connection skills or releasing negative emotions, 
feelings, and frustration through positive connection activities [9]. These activities considerably enhanced interpersonal support, enabling older adults to learn additional methods of self-management and reduce depression $[8,19]$. Other studies revealed that love language serves as a springboard for positive interpersonal relationship development leading to reduced psychological problems $(7,9,10,14)$.

Lastly, the success of this program may be linked to the inherent nature of Thai multicultural community both in Thai-Buddhism and Thai-Muslim rural community context. Everyone in the community is relative, so they should normally take care of one another. Closely-knit relationship and high responsibilities of grandchildren to their older adults at home still play a strong role despite massive changes brought about by globalization [3,6,7]. Grandchildren still influence older adult's ways of life if their older adults receive love and trust from the grandchildren and family $[7,13]$. Thai grandchildren still treat older adults with respect even if they want to be independent and older adults still need good relationships [4,6]. Information recorded by the depressed older adults and their grandchildren in the handbooks revealed definite relationship cohesiveness and a strong positive bond between depressed older adults and their grandchildren. There has been empirical evidence to support that grandchildren are key persons for guiding, practicing support, and emotionally supporting to enhance a person's ability to cope with depression or to alleviate the impact of stressful events on older adults [5,13]. The depressed older adults in treatment group seemed to learn when they perceive positive connection and needs in life to become stable and happy $[5,8]$. This insight apparently motivated them to change their negative connection, emotions, thoughts and behaviors $[7,8,20]$.

\section{Conclusion, limitations and implications}

In summary, love language of grandchildren can be effective in reducing mild to moderate depression among older adults in Thai family and rural community who are left untreated and may be at risk for severe depression. General interpretation of these findings is restricted to the study's timeframe, so it would be quite premature to evaluate the potential long-term preventive effects of the treatment. Following the results in a longitudinal design for at least 1 year is another way that will be useful to confirm the effectiveness of the treatment. Future research should examine how the love language of grandchildren program differs across different levels of depression, as well as other psychological problems. Health care personnel and involving persons need to focus and raise awareness of people in the community to promote psychological well-being in older adults with love language treatment as a daily routine. In this way, grandchildren's love language treatment not only enhance positive interpersonal relationship paving the way to depression prevention among older adults but also empower meaning of life among depressed older adults suffering from mild to moderate severity of depression.

\section{Acknowledgements}

This research was funded by the Office of the Higher Education Commission (OHEC), Thailand.

\section{References}

[1] World Health Organization. Depression let's talk: Campaign essentials, Available at: http://www.who.int/campaigns/world-health-day/2017/toolkit.pdf?ua=1, accessed April 2017.

[2] Department of Mental Health. E-Reports service, Available at https://www.dmh.go.th/report, accessed December 2017.

[3] A Bunloet. Prevalence and factors associated with depression among the elderly community residents with chronic diseases in Samliam Urban Primary Care Unit, Khon Kaen. Srinagarind Med J. 2016; 31, 25-33.

[4] N Wongpanarak and S Chaleoykitti. Depression: A significant mental health problem of elderly. $J$. Roy. Thai Arm. Nurs. 2014; 15, 24-31.

[5] Y Ni, JY Tein, M Zhang, Y Yang and G Wu. Changes in depression among older adults in China: A latent transition analysis. J. Affect. Disord. 2017; 209, 3-9. 
[6] K Yodmai and R Somrongthong. Depression and factors associated with the quality of life among the elderly in Numpong and Somsoong District, Khon Kaen Province, Thailand. Eur. J. Sci. Res. 2016; 138, 193-9.

[7] P Koolnaphadol. An enhancement of family quality of life through love language program. J. Educ. Measur. Mahasarakham Univ. 2016; 22, 233-46.

[8] I Reiner, MJ Bakermans-Kranenburg, MH Van Ijzendoorn, E Fremmer-Bombik and M Beutel. Adult attachment representation moderates psychotherapy treatment efficacy in clinically depressed inpatients. J. Affect. Disord. 2016; 195, 163-71.

[9] SS Bhar and GK Brown. Treatment of depression and suicide in older adults. Cog. Behav. Pract. 2012; 19, 116-25.

[10] JW Kanter, G Holman and KG Wilson. Where is the love? Contextual behavioral science and behavior analysis. J Context. Behav. Sci. 2014; 3, 69-73.

[11] TJ Taylor. Languaging, Metalanguaging Linguistics, and Love. Lang. Sci. 2017; 61, 1-4.

[12] E Gareis and R Wilkins. Love expression in the United States and Germany. Int. J. Intercult. Relat. $2011 ; 35,307-19$.

[13] A Izquierdo, J Miranda, E Bromley, C Sherbourne, G Ryan, D Kennedy and K Wells. Grandparenting experiences among adults with a history of depression: A mixed-methods study. Gen. Hosp. Psychiat. 2015; 37, 185-91.

[14] G Chapman. The 5 Love Languages: The Secret to Love that Lasts. Northfield Publishing, Chicago, 2015, p. 35-87.

[15] Department of Mental Health. The Nine-Question Scale (9Q), Available at https://www.dmh.go.th/test/ download/files/2Q\%209Q\%208Q\%20(1).pdf, accessed August 2020.

[16] M Lotrakul, P Sukanich and C Sukying. The reliability and validity of Thai version of Hamilton Rating Scale for Depression. J. Psychiatr. Assoc. Thailand 1996; 41, 235-46.

[17] J Cohen. A power primer. Psychol. Bull. 1992; 112, 155-9.

[18] MA Hamilton. Rating scale for depression. J. Neurol. Neurosurg. Psychiat. 1960; 23, 56-62.

[19] S Joshi, SJ Mooney, AG Rundle, JW Quinn, JR Beard and M Cerda. Pathways from neighborhood poverty to depression among older adults. Health Place 2017; 43, 138-43.

[20] J Apostolo, E Bobrowicz-Campos, M Rodrigues, I Castro and D Cardoso. The effectiveness of nonpharmacological treatments in older adults with depressive disorders: A systematic review. Int. J. Nurs. Stud. 2016; 58, 59-70. 